\title{
Association between Sugar-Sweetened Beverage Consumption and Executive Function in Children
}

\author{
Zhaohuan Gui, Shan Huang, Yican Chen, Yu Zhao, Nan Jiang, Shuxin Zhang and Yajun Chen *D \\ Department of Maternal and Child Health, School of Public Health, Sun Yat-sen University, \\ Guangzhou 510080, China; guizhh@mail2.sysu.edu.cn (Z.G.); huangsh59@mail2.sysu.edu.cn (S.H.); \\ chenyc55@mail2.sysu.edu.cn (Y.C.); zhaoy369@mail2.sysu.edu.cn (Y.Z.); jiangn63@mail2.sysu.edu.cn (N.J.); \\ zhangshx26@mail2.sysu.edu.cn (S.Z.) \\ * Correspondence: chenyj68@mail.sysu.edu.cn
}

Citation: Gui, Z.; Huang, S.; Chen, Y.; Zhao, Y.; Jiang, N.; Zhang, S.; Chen, Y. Association between Sugar-Sweetened Beverage Consumption and Executive Function in Children. Nutrients 2021, 13, 4563. https://doi.org/10.3390/ nu13124563

Academic Editor: Bo Chen

Received: 25 October 2021

Accepted: 15 December 2021

Published: 20 December 2021

Publisher's Note: MDPI stays neutral with regard to jurisdictional claims in published maps and institutional affiliations.

Copyright: (c) 2021 by the authors. Licensee MDPI, Basel, Switzerland. This article is an open access article distributed under the terms and conditions of the Creative Commons Attribution (CC BY) license (https:/ / creativecommons.org/licenses/by/ $4.0 /)$.

\begin{abstract}
The association between sugar-sweetened beverages (SSB) and executive function among children has been less investigated. We aimed to explore this topic. We randomly recruited 6387 children aged 6-12 years from five elementary schools in Guangzhou, China in 2019. Information on frequency and servings of children's SSB consumption was assessed using a questionnaire. Children's executive function was evaluated using parents' ratings of the Behavioral Rating Inventory of Executive Function (BRIEF), which comprises eight subscales-including inhibit, shift, emotional control, initiate, working memory, plan/organize, organization of materials and monitor, as well as three composite indexes including behavioral regulation index (BRI), metacognition index (MI), and global executive index (GEC). SSB consumption was positively associated with all subscales and composite scores of BRIEF as well as higher risks of elevated executive difficulties, indicating poorer executive function. For example, children who drank SSB $\geq 2$ times/week were related to higher scores of GEC (estimates, 95\% confidence interval (CI): $2.44,1.79$ to 3.09) compared with those who never drank SSB. The odds ratio of elevated GEC associated with SSB consumption $\geq 2$ times/week was 1.62 (95\% CI: $1.34,1.96)$ than non-consumers. The results of this study indicated that SSB consumption was associated with poorer executive function in children.
\end{abstract}

Keywords: children; executive function; sugar-sweetened beverages

\section{Introduction}

The consumption of sugar-sweetened beverages (SSB) has been decreasing in most Western countries during the past two decades [1-3], but SSB is the major contributor of added sugar in the American diet and its consumption has been increasing worldwide [4-6]. The harmful impact of SSB on cardiometabolic health has been well documented, and it is associated with greater risks of obesity [7], hypertension [8], type 2 diabetes (independently of adiposity) [9], and cardiometabolic death [10]. An estimation based on globally representative data calculated that about 184,000 yearly deaths worldwide in 2010 were attributed to SSB consumption, and three quarters of this burden occurred in low- and middle-income countries [11]. This could be explained by the following several factors: (1) SSB has poor satiating property that can be consumed excessively [12]; (2) SSB displaces more nutritional foods and beverages [13]; and (3) SSB contain high levels of fructose [14,15], and fructose metabolism results in detrimental health outcomes at the organ and metabolic level [16].

In contrast to extensive research on the physical health impacts of SSB consumption, the association between SSB consumption and executive function has been less investigated. Executive function is an umbrella term involving a variety of interrelated, higher-level cognitive skills that were requisite for complex reasoning, goal-oriented activity, and self-regulatory behavior $[17,18]$. Although the windows of neurodevelopmental vulnerability occur during prenatal and early postnatal periods [19], high-order executive skills develop significantly from ages 6 to 10 which makes this period especially sensitive to 
perturbation [20]. Animal studies have shown that sugar could induce the increases in mediators of inflammation (e.g., IL-6 and IL-1 $\beta$ ) and oxidative stress as well as decrease in neurotrophins, and these intermediate factors subsequently altered brain structure and function [21-23]. Therefore, it is reasonable to hypothesize that excessive consumption of SSB may harmfully impact the performance on executive function. To our knowledge, there were limited epidemiological studies investigating the association between SSB consumption and executive function in children [24-27], and results were inconsistent. In addition, the majority of these studies were implemented in high-income countries, and such studies from low- and middle-income countries such as China were scarce, where the level of SSB consumption was relatively low [5]. We therefore aimed to investigate the association between SSB consumption and executive function in children by using data from a cross-sectional study in Guangzhou, Southern China.

\section{Materials and Methods}

\subsection{Study Design and Population}

Data comes from a cross-sectional study, which was implemented in Guangzhou, southern China from April to May 2019. We performed a two-stage cluster sampling strategy to recruit study participants. First, we randomly selected five districts including three urban areas and two suburban areas in Guangzhou city. Second, we randomly selected one elementary school within each district, which generated five elementary schools. Finally, all students from the selected five schools were invited to participate. The above sampling strategy generated 8692 eligible participants, of whom 6883 children and parents agreed to participate, giving a response rate of $79.2 \%$. We additionally excluded 496 children without information on SSB, executive function or possible important confounders, leaving a final sample of 6387 participants aged 6-12 years (Figure 1).

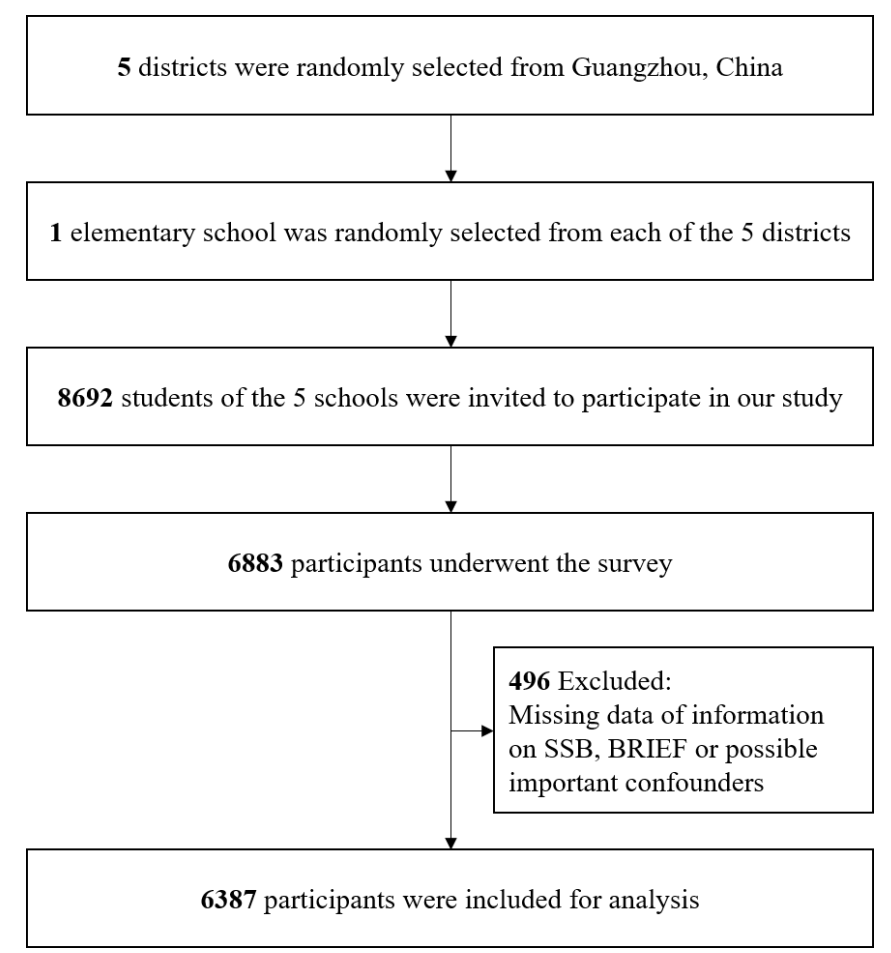

Figure 1. Flowchart of participant inclusion.

Approve for this study was granted by the Ethical Review Committee for Biomedical Research, Sun Yat-sen University. The study has been registered with China Clinical Trial Registry NCT03582709. Prior to data collection, all children and their parents/guardians gave the written informed consent. 


\subsection{Sugar-Sweetened Beverage Consumption}

The following two questions, reported by children and their parents, were used to assess SSB consumption. Participants were asked about the frequency of SSB consumption from the question "In the past 7 days, how many times did your child drink SSB such as Coke, Sprite, Fruit drinks (Orange juice drink etc.), Nutrition Express, Red Bull?". If they answered more than 0 times, they were further asked about the servings of SSB each time consumed from the question "On average, how many servings of SSB did your child drink each time? (One serving is equal to $250 \mathrm{~mL}$ )". The distribution of SSB consumption status was highly skewed, and transformation of data was not feasible owing to the large number of people who reported never drinking SSB. Therefore, the frequency of SSB consumption was aggregated and then a new intake category was categorized in order to ensure an adequate number of participants in each group. SSB consumption was examined as a threelevel variable: 0 time/week, 1 time/week, and $\geq 2$ times/week. In addition, we calculated the total servings of SSB intake weekly (servings/week) using the product of times of SSB intake per week by the servings of SSB intake each time.

\subsection{Executive Function}

We used a parent-rated Behavioral Rating Inventory of Executive Function (BRIEF) to assess children's executive function. The parental form of BRIEF provides an ecological assessment of executive function in everyday settings at home for children at 5 and 18 years of age [28]. It is valid, reliable [28], and widely used in epidemiological and clinical studies [29]. The BRIEF has been translated into Chinese and documented to have a high value of internal consistency, with Cronbach's $\alpha$ from 0.70 to 0.96 [30]. The BRIEF comprises 86 items, which were grouped into eight subscales and three composite indexes. Scores of interest for this study were the behavioral regulation index (BRI), a sum of inhibit, shift, and emotional control subscales; the metacognition index (MI), a sum of initiate, working memory, plan/organize, organization of materials, and monitor subscales; and global executive composite (GEC), a sum of all eight subscale scores. The BRI, MI, and GEC were converted into T-scores (mean $=50$, standard deviation $(\mathrm{SD})=10$ ) and standardized by age and sex. Higher scores indicate more problems of executive function. Scores $\geq 60$ (e.g., $1 \mathrm{SD}$ from the mean) were classified as 'elevated executive difficulties'.

\subsection{Covariates}

Via questionnaires, we obtained the following information on sociodemographic factors and lifestyles including age (years), sex (boys or girls), siblings ( 0 or $\geq 1)$, monthly household income ( $<5000 \mathrm{RMB}, 5000-7999 \mathrm{RMB}, 8000-11,999 \mathrm{RMB}, \geq 12,000 \mathrm{RMB}$ or refused to answer), parental education (highest degree of each parent: below senior high, senior high, college, university or above), parental smoking status (never smokers if neither parent smoked, former or current smokers if either of parents were former or current smokers), outdoor exercise ( $<1 \mathrm{~h} /$ day, $1-1.9 \mathrm{~h} /$ day, $2-4 \mathrm{~h} /$ day, or $>4 \mathrm{~h} /$ day), and dietary intakes (times/week). Information on dietary intakes was collected separately by 3 questions "In the past 7 days, how many times did your child eat (1) fried food; (2) fish or fish products; and (3) milk, or dairy-products?". Body height and weight were measured with children lightly dressed and in bare feet, and body mass index (BMI) was calculated as weight in kilograms divided by height in meters.

\subsection{Statistical Analyses}

Differences in basic characteristics by SSB consumption groups were analyzed by using analysis of variance for continuous data and the chi-square test for categorical data. Data were presented as mean and SD for continuous variables or as number and percentage for categorical variables.

To examine the associations between SSB consumption and executive function, we performed general linear regression models for continuous data (BRIEF scores) as well as logistic regression models for binary data (elevated executive difficulties). The 0 time/week 
group was treated as the reference group, and model estimates were presented as regression coefficients $(\beta \mathrm{s})$ or odds ratio (OR) and $95 \%$ confidence intervals (CIs). Three models of increasing covariates adjustment were conducted. With no adjustment in the unadjusted model, Model 1 included sex, age, only child, monthly household income, parental education, parental smoking status, outdoor exercise, and BMI as control variables. Model 2 included fried food, fish or fish products, and milk, or dairy-products as additional control variables. We performed trend tests by entering ordinal categorical variables as continuous variables in the three models. We then restricted to children who reported drinking SSB to assess the dose-response relationship between the total servings of SSB consumption a week (as a continuous variable) and executive function.

We performed subgroup analyses by sex (boys, girls), age ( $<10$ years, $\geq 10$ years), and BMI (normal weight, overweight/obesity) and also examined the effect modification by incorporating a multiplicative interaction term for SSB $\times$ modifier in the adjusted model.

Data analyses were conducted with SAS software (version 9.4, SAS Institute). All criteria for statistical significance were set at a two-tailed $p<0.05$.

\section{Results}

\subsection{Description of Study Participants}

Among 6387 participants, the mean (SD) age was $8.6(1.5)$ years, and $3410(53.4 \%)$ were boys. A total of $4116(64.4 \%)$ children reported consuming SSB, with $1918(30.0 \%)$ having 1 time a week and $2198(34.4 \%)$ having no less than 2 times a week (Table 1$)$. The mean (SD) of servings of SSB intake a week among SSB consumers was 2.45 (2.57) (data not shown). Compared to non-consumers, children who consumed SSB were more likely to be older, boys, born to parents who smoked, and to have higher BMI, higher intakes of fried food, fish or fish products, and milk, or dairy-products (all $p$ values $<0.05$ ). The distribution of scores of BRIEF among SSB consumption is presented in Table A1.

Table 1. Study population characteristics according to SSB consumption.

\begin{tabular}{|c|c|c|c|c|c|}
\hline \multirow{2}{*}{ Characteristics } & \multirow{2}{*}{ Total Sample } & \multicolumn{3}{|c|}{ SSB Consumption } & \multirow{2}{*}{$p$ Value } \\
\hline & & 0 Time/Week & 1 Time/Week & $\geq 2$ Times/Week & \\
\hline$n$ & 6387 & $2271(35.6)$ & $1918(30.0)$ & $2198(34.4)$ & \\
\hline Age (years) & $8.6 \pm 1.5$ & $8.4 \pm 1.5$ & $8.5 \pm 1.5$ & $8.9 \pm 1.5$ & $<0.0001$ \\
\hline Sex & & & & & $<0.0001$ \\
\hline Boys & $3410(53.4)$ & $1121(49.4)$ & $1019(53.1)$ & $1270(57.8)$ & \\
\hline Girls & $2977(46.6)$ & $1150(50.6)$ & $899(46.9)$ & $928(42.2)$ & \\
\hline Siblings & & & & & 0.090 \\
\hline 0 & $2701(42.4)$ & $922(40.8)$ & $814(42.5)$ & $965(44.0)$ & \\
\hline$\geq 1$ & $3666(57.6)$ & $1338(59.2)$ & $1102(57.5)$ & $1226(56.0)$ & \\
\hline Monthly household income & & & & & 0.053 \\
\hline$<5000 \mathrm{RMB}$ & $848(13.3)$ & $298(13.2)$ & $259(13.6)$ & $291(13.3)$ & \\
\hline 5000-7999 RMB & $1366(21.5)$ & $478(21.1)$ & $410(21.4)$ & $478(21.8)$ & \\
\hline 8000-11,999 RMB & $1299(20.4)$ & $428(18.9)$ & $385(21.0)$ & $486(22.2)$ & \\
\hline$\geq 12,000 \mathrm{RMB}$ & $2250(35.3)$ & $813(36.0)$ & $700(36.5)$ & $737(33.6)$ & \\
\hline Refused to answer & $604(9.5)$ & $243(10.8)$ & $162(8.5)$ & $199(9.1)$ & \\
\hline Parental education & & & & & 0.310 \\
\hline Below senior high school & $181(2.8)$ & $60(2.7)$ & $57(3.0)$ & $64(2.9)$ & \\
\hline Senior high school & $659(10.4)$ & $228(10.1)$ & $179(9.3)$ & $252(11.5)$ & \\
\hline College & $1164(18.3)$ & 405 (17.9) & $369(19.3)$ & $390(17.8)$ & \\
\hline University or above & $4363(68.5)$ & $1567(69.3)$ & $1311(68.4)$ & $1485(67.8)$ & \\
\hline Parental smoking status & & & & & $<0.0001$ \\
\hline Never smokers & $3716(58.4)$ & $1423(38.3)$ & $1116(30.0)$ & 1177 (31.7) & \\
\hline Former smokers & $749(11.8)$ & $233(31.1)$ & $224(29.9)$ & $292(39.0)$ & \\
\hline Current smokers & $1902(29.9)$ & $604(31.8)$ & $576(30.3)$ & $722(38.0)$ & \\
\hline Outdoor exercise & & & & & 0.975 \\
\hline$<1 \mathrm{~h} /$ day & $2743(43.1)$ & $965(35.2)$ & $838(30.6)$ & $940(34.3)$ & \\
\hline $1-1.9 \mathrm{~h} /$ day & $2807(44.1)$ & $1001(35.7)$ & $836(29.8)$ & $970(34.6)$ & \\
\hline $2-4 \mathrm{~h} /$ day & $609(9.6)$ & $215(35.3)$ & $180(29.6)$ & $214(35.1)$ & \\
\hline$>4 \mathrm{~h} /$ day & $208(3.3)$ & $144(69.9)$ & $39(18.9)$ & $23(11.2)$ & \\
\hline $\mathrm{BMI}\left(\mathrm{kg} / \mathrm{m}^{2}\right)$ & $16.8 \pm 3.0$ & $16.6 \pm 3.0$ & $16.7 \pm 2.9$ & $17.1 \pm 3.1$ & $<0.0001$ \\
\hline Fried food (times / week) & $0.8 \pm 1.0$ & $0.4 \pm 0.8$ & $0.7 \pm 0.8$ & $1.2 \pm 1.2$ & $<0.0001$ \\
\hline Fish or fish products (times/week) & $3.0 \pm 2.1$ & $2.9 \pm 2.1$ & $2.9 \pm 2.0$ & $3.1 \pm 2.1$ & 0.0001 \\
\hline Milk, or dairy-products (times/week) & $6.5 \pm 3.3$ & $6.5 \pm 7.0$ & $6.3 \pm 3.3$ & $6.6 \pm 3.2$ & 0.014 \\
\hline
\end{tabular}

Note: Descriptive statistics are presented as mean (standard deviation) and number (percentage) for continuous and categorical. variables, respectively. Abbreviations: BMI, body mass index; SSB, sugar-sweetened beverages. 


\subsection{Association between SSB Consumption and Executive Function}

SSB consumption was significantly associated with inferior performance on executive function (Table 2, Table 3, and Table A2). In the adjusted model 2, children who drank SSB 1 time a week was positively related to all subscales and composite scores of BRIEF including inhibit, shift, emotional control, initiate, working memory, plan/organize, organization of materials, monitor, BRI, MI and GEC, with estimates ranging from 0.82 ( $95 \%$ CI: 0.18 , $1.46)$ to 1.22 (95\% CI: $0.59,1.86)$, relative to participants who never drank SSB ( $p$-values for all tests were $<0.05$ ) (Table 2). Similarly, children who drank SSB $\geq 2$ times/week was positively associated with all subscales and composite scores of BRIEF, with estimates ranging from 1.55 (95\% CI: 0.91, 2.19) to 2.50 (95\% CI: 1.86, 3.14), compared to those children who were non-consumers ( $p$-values for all trend tests $<0.05$ ). When only the children who had a habit of drinking SSB were analyzed, we found that each serving increase in SSB consumption was positively associated with all scores of BRIEF, with the estimates ranging from 0.21 (95\% CI: $0.03,0.40)$ to 0.35 (95\% CI: 0.16, 0.54) (Table A2).

Table 2. Association between SSB consumption with executive function $(n=6387)$.

\begin{tabular}{|c|c|c|c|}
\hline \multirow{2}{*}{ Executive Function } & \multicolumn{3}{|c|}{ Estimates (95\% Confidence Interval) } \\
\hline & Crude Model & Model $1^{a}$ & Model $2^{b}$ \\
\hline \multicolumn{4}{|l|}{ Inhibit } \\
\hline 0 time/week & 0 (Reference) & 0 (Reference) & 0 (Reference) \\
\hline 1 time/week & $1.03(0.42,1.64)^{\mathrm{C}}$ & $0.97(0.35,1.59)^{\mathrm{c}}$ & $0.87(0.26,1.52)^{\mathrm{C}}$ \\
\hline$\geq 2$ times/week & $1.76(1.18,2.35)^{\mathrm{C}}$ & $1.73(1.12,2.33)^{c}$ & $1.55(0.91,2.19)^{\mathrm{C}}$ \\
\hline$p$ for trend & $<0.0001$ & $<0.0001$ & $<0.0001$ \\
\hline \multicolumn{4}{|l|}{ Shift } \\
\hline 0 time/week & 0 (Reference) & 0 (Reference) & 0 (Reference) \\
\hline 1 time/week & $1.24(0.64,1.84)^{\mathrm{C}}$ & $1.15(0.53,1.77)^{\mathrm{c}}$ & $1.03(0.41,1.66)^{\mathrm{C}}$ \\
\hline$\geq 2$ times/week & $2.11(1.53,2.68)^{\mathrm{C}}$ & $1.97(1.37,2.57)^{c}$ & $1.72(1.08,2.36)^{\mathrm{C}}$ \\
\hline$p$ for trend & $<0.0001$ & $<0.0001$ & $<0.0001$ \\
\hline \multicolumn{4}{|l|}{ Emotional control } \\
\hline 0 time/week & 0 (Reference) & 0 (Reference) & 0 (Reference) \\
\hline 1 time/week & $1.01(0.40,1.62)^{\mathrm{c}}$ & $0.95(0.32,1.59)^{\mathrm{c}}$ & $0.82(0.18,1.46)^{\mathrm{c}}$ \\
\hline$\geq 2$ times/week & $1.80(1.22,2.39)^{\mathrm{C}}$ & $1.90(1.29,2.52)^{\mathrm{c}}$ & $1.67(1.02,2.32)^{\mathrm{C}}$ \\
\hline $\bar{p}$ for trend & $<0.0001$ & $<0.0001$ & $<0.0001$ \\
\hline \multicolumn{4}{|l|}{ Initiate } \\
\hline 0 time/week & 0 (Reference) & 0 (Reference) & 0 (Reference) \\
\hline 1 time/week & $1.26(0.66,1.85)^{c}$ & $1.23(0.61,1.84)^{\mathrm{C}}$ & $1.10(0.48,1.72)^{c}$ \\
\hline$\geq 2$ times/week & $2.49(1.92,3.07)^{\mathrm{C}}$ & $2.39(1.79,2.98)^{c}$ & $2.16(1.53,2.80)^{\mathrm{C}}$ \\
\hline $\bar{p}$ for trend & $<0.0001$ & $<0.0001$ & $<0.0001$ \\
\hline \multicolumn{4}{|l|}{ Working memory } \\
\hline 0 time/week & 0 (Reference) & 0 (Reference) & 0 (Reference) \\
\hline 1 time/week & $1.24(0.63,1.84)^{\mathrm{c}}$ & $1.25(0.63,1.87)^{\mathrm{C}}$ & $1.10(0.48,1.73)^{c}$ \\
\hline$\geq 2$ times/week & $2.25(1.67,2.83)^{\mathrm{C}}$ & $2.27(1.67,2.87)^{c}$ & $2.01(1.38,2.64)^{c}$ \\
\hline$p$ for trend & $<0.0001$ & $<0.0001$ & $<0.0001$ \\
\hline \multicolumn{4}{|l|}{ Plan/organize } \\
\hline 0 time/week & 0 (Reference) & 0 (Reference) & 0 (Reference) \\
\hline 1 time/week & $1.33(0.74,1.93)^{\mathrm{c}}$ & $1.23(0.62,1.84)^{\mathrm{C}}$ & $1.12(0.51,1.74)^{\mathrm{C}}$ \\
\hline$\geq 2$ times/week & $2.86(2.29,3.43)^{c}$ & $2.69(2.09,3.28)^{c}$ & $2.47(1.84,3.10)^{C}$ \\
\hline$p$ for trend & $<0.0001$ & $<0.0001$ & $<0.0001$ \\
\hline \multicolumn{4}{|l|}{ Organization of materials } \\
\hline 0 time/week & 0 (Reference) & 0 (Reference) & 0 (Reference) \\
\hline 1 time/week & $1.19(0.60,1.79)^{\mathrm{c}}$ & $1.09(0.48,1.71)^{\mathrm{C}}$ & $1.00(0.38,1.63)^{c}$ \\
\hline$\geq 2$ times/week & $2.60(2.02,3.17)^{\mathrm{C}}$ & $2.48(1.88,3.08)^{c}$ & $2.27(1.64,2.90)^{\mathrm{C}}$ \\
\hline $\bar{p}$ for trend & $<0.0001$ & $<0.0001$ & $<0.0001$ \\
\hline
\end{tabular}


Table 2. Cont.

\begin{tabular}{|c|c|c|c|}
\hline \multirow{2}{*}{ Executive Function } & \multicolumn{3}{|c|}{ Estimates (95\% Confidence Interval) } \\
\hline & Crude Model & Model $1^{a}$ & Model $2^{b}$ \\
\hline \multicolumn{4}{|l|}{ Monitor } \\
\hline 0 time/week & 0 (Reference) & 0 (Reference) & 0 (Reference) \\
\hline 1 time/week & $1.27(0.67,1.86)^{\mathrm{C}}$ & $1.17(0.57,1.78)^{\mathrm{C}}$ & $1.11(0.50,1.72)^{\mathrm{C}}$ \\
\hline$\geq 2$ times/week & $2.37(1.80,2.94)^{\mathrm{C}}$ & $2.13(1.55,2.72)^{c}$ & $1.99(1.37,2.61)^{\mathrm{C}}$ \\
\hline$p$ for trend & $<0.0001$ & $<0.0001$ & $<0.0001$ \\
\hline \multicolumn{4}{|l|}{ BRI } \\
\hline 0 time/week & 0 (Reference) & 0 (Reference) & 0 (Reference) \\
\hline 1 time/week & $1.22(0.61,1.83)^{\mathrm{c}}$ & $1.15(0.52,1.78)^{\mathrm{C}}$ & $1.02(0.39,1.66)^{c}$ \\
\hline$\geq 2$ times $/$ week & $2.13(1.54,2.72)^{\mathrm{c}}$ & $2.11(1.50,2.73)^{c}$ & $1.87(1.22,2.51)^{\mathrm{C}}$ \\
\hline$p$ for trend & $<0.0001$ & $<0.0001$ & $<0.0001$ \\
\hline \multicolumn{4}{|l|}{ MI } \\
\hline 0 time/week & 0 (Reference) & 0 (Reference) & 0 (Reference) \\
\hline 1 time/week & $1.38(0.77,1.99)^{\mathrm{c}}$ & $1.31(0.69,1.93)^{\mathrm{c}}$ & $1.18(0.55,1.81)^{c}$ \\
\hline$\geq 2$ times/week & $2.90(2.31,3.49)^{\mathrm{c}}$ & $2.75(2.14,3.35)^{\mathrm{C}}$ & $2.50(1.86,3.14)^{\mathrm{C}}$ \\
\hline$p$ for trend & $<0.0001$ & $<0.0001$ & $<0.0001$ \\
\hline \multicolumn{4}{|l|}{ GEC } \\
\hline 0 time/week & 0 (Reference) & 0 (Reference) & 0 (Reference) \\
\hline 1 time/week & $1.42(0.80,2.04)^{\mathrm{c}}$ & $1.37(0.74,2.00)^{\mathrm{C}}$ & $1.22(0.59,1.86)^{c}$ \\
\hline$\geq 2$ times/week & $2.85(2.25,3.45)^{\mathrm{C}}$ & $2.72(2.10,3.34)^{c}$ & $2.44(1.79,3.09)^{\mathrm{c}}$ \\
\hline$p$ for trend & $<0.0001$ & $<0.0001$ & $<0.0001$ \\
\hline
\end{tabular}

Abbreviations: BRI, behavioral regulation index; GEC: global executive composite; HI: hyperactivity index; $\mathrm{MI}_{x}$ metacognition; SSB, sugar-sweetened beverages. ${ }^{a}$ Adjusted for sex, age, siblings, monthly household income, parental education, parental smoking status, outdoor exercise and body mass index. ${ }^{\mathrm{b}}$ Additionally adjusted for fried food, fish or fish products, and milk, or dairy-products. ${ }^{\mathrm{c}}$ Statistically significant association $(p$-value $<0.05)$.

Table 3. Association between SSB consumption with executive dysfunction $(n=6387)$.

\begin{tabular}{|c|c|c|c|}
\hline \multirow{2}{*}{ Executive Dysfunction } & \multicolumn{3}{|c|}{ Odds Ratio (95\% Confidence Interval) } \\
\hline & Crude Model & Model $1^{\text {a }}$ & Model $2^{b}$ \\
\hline \multicolumn{4}{|l|}{ Elevated BRI } \\
\hline 0 time/week & 1.00 (Reference) & 1.00 (Reference) & 1.00 (Reference) \\
\hline 1 time/week & $1.25(1.05,1.48)^{c}$ & $1.27(1.05,1.54)^{\mathrm{c}}$ & $1.23(1.02,1.50)^{c}$ \\
\hline$\geq 2$ times/week & $1.54(1.31,1.81)^{\mathrm{c}}$ & $1.55(1.29,1.86)^{\mathrm{c}}$ & $1.45(1.19,1.76)^{\mathrm{C}}$ \\
\hline$p$ for trend & $<0.0001$ & $<0.0001$ & 0.0002 \\
\hline \multicolumn{4}{|l|}{ Elevated MI } \\
\hline 0 time/week & 1.00 (Reference) & 1.00 (Reference) & 1.00 (Reference) \\
\hline 1 time/week & $1.21(1.02,1.44)^{\mathrm{c}}$ & $1.22(1.01,1.48)^{c}$ & $1.21(1.00,1.47)^{c}$ \\
\hline$\geq 2$ times/week & $1.74(1.49,2.04)^{\mathrm{c}}$ & $1.72(1.44,2.05)^{\mathrm{c}}$ & $1.70(1.41,2.05)^{c}$ \\
\hline $\bar{p}$ for trend & $<0.0001$ & $<0.0001$ & $<0.0001$ \\
\hline \multicolumn{4}{|l|}{ Elevated GEC } \\
\hline 0 time/week & 1.00 (Reference) & 1.00 (Reference) & 1.00 (Reference) \\
\hline 1 time/week & $1.13(0.94,1.35)$ & $1.15(0.95,1.40)$ & $1.14(0.94,1.39)$ \\
\hline$\geq 2$ times/week & $1.68(1.42,1.98)^{\mathrm{C}}$ & $1.67(1.40,2.00)^{\mathrm{C}}$ & $1.62(1.34,1.96)^{c}$ \\
\hline$p$ for trend & $<0.0001$ & $<0.0001$ & $<0.0001$ \\
\hline
\end{tabular}

Abbreviations: BRI, behavioral regulation index; GEC: global executive composite; MI, metacognition; SSB sugar-sweetened beverages. ${ }^{\text {a }}$ Adjusted for sex, age, siblings, monthly household income, parental education, parental smoking status, outdoor exercise and body mass index. ${ }^{\mathrm{b}}$ Additionally adjusted for fried food, fish or fish products, and milk, or dairy-products. ${ }^{c}$ Statistically significant association ( $p$ value $\left.<0.05\right)$.

The odds ratios of elevated BRI and elevated MI in children who drank SSB 1 time a week were 1.23 (95\% CI: $1.02,1.50)$ and 1.21 (95\% CI: 1.00, 1.47), respectively, compared to their counterparts who never drank SSB in the adjusted model 2 ( $p$ values for all tests were $<0.05$ ) (Table 3). Additionally, the odds ratios of elevated BRI, elevated MI, and elevated GEC in children who drank SSB $\geq 2$ times a week were 1.45 (95\% CI: 1.19, 1.76), 1.70 (95\% CI: $1.41,2.05)$ and 1.62 (95\% CI:1.34, 1.96), respectively, compared to children who were non-consumers ( $p$-values for all trend tests $<0.05$ ). 


\subsection{Effect Modification}

We further assessed potential modification effects between SSB consumption with sex, age, and BMI on executive function. However, no significant modification effects were observed for sex, age, or BMI (Table A3).

\section{Discussion}

In our cross-sectional analysis of the large population-based sample, we observed that higher consumption of SSB was associated with poorer performance on executive function and high risk of executive dysfunction in children. The association between SSB consumption and executive function remained robust after adjustment for a wide range of covariates including sociodemographic factors, lifestyles, and diets.

In this large sample of nearly 6000 school children, about two-thirds of children reported consuming SSB, which was comparable with the study conducted among American children [31]. To our knowledge, there were a few studies examining the association between SSB consumption and executive function in children, and these studies yielded inconsistent observations [24-27]. For example, in agreement with the current results, a population-based cohort study of 1234 children in the US reported that each additional SSB serving consumed per day in early childhood was associated with a 2.4-point decrease in verbal intelligence evaluated by Kaufman Brief Intelligence Test at mid-childhood [25]. In another study conducted in Kuwait among 1370 adolescents aged 11-16 years, consumption of soft sugar drinks was inversely associated with non-verbal intelligence assessed by Raven's Standard Progressive Matrices [24]. In contrast, an earlier meta-analysis that pooled 16 interventions found no overall association between sugar and glucose with cognition, although the control group in the concluded studies were administrated artificial sweeteners [27]. Similarly, in a recent study of 868 school children aged 8 to 10 years in the US, there was no significant association between SSB consumption and cognitive or academic outcomes including working memory, inhibitory control, mathematics, or English language arts score [26]. There were several differences between the described studies that could explain the inconsistent findings. These included the heterogeneity in study population (e.g., age, genetic background, and lifestyles), methods in quantifying SSB consumption as well as the instruments of executive function measurement. The findings of our study combining the studies mentioned above support the negative association between SSB consumption and executive function among children.

The biological mechanism underlying the relationship between SSB consumption and executive function are yet to be established. Increases in inflammation and oxidative stress, as well as decreases in neurotrophins, are the most plausible pathways proposed by previous studies [21,22,32]. Specifically, evidence from an animal study demonstrated that rats fed with sucrose-fructose drinks had increased mediators of inflammation in the dorsal hippocampus including IL-6 and IL-1 $\beta$ [21]. Rats exposed to a fructose-sweetened solution also displayed an increased level of oxidative stress and advanced glycation end products as well as decreased antioxidant enzymes in the frontal cortex [22]. Moreover, studies on rodent models have evidenced that fructose administration in rats was associated with a reduction in the hippocampal brain-derived neurotrophic factor, a protein that supports synaptic plasticity and circuit information [32]. These intermediators subsequently affect the executive function.

This study had several potential limitations. First, the cross-sectional study design cannot be used to infer the causality of SSB consumption and executive function, prospective cohort study or randomized controlled study in the future would be need to establish that level of causality inference. Second, recall bias and information bias from assessment of SSB consumption, parent-rated executive function, and questionnaire-based sociodemographic factors might be evitable. Third, SSB consumption was self-reported, and we did not objectively measure the concentrations of such exposure. Fourth, we did not measure other sources of sugar, and therefore intake of foods high in sugar could not be accounted for. 
Fifth, though a wide range of covariates were carefully adjusted in the model, residual confounding caused by unavailable data, such as parental mental health status, could exist.

\section{Conclusions}

In conclusion, the findings of this study found that SSB consumption was associated with poorer performance on executive function among children. Because excessive consumption of SSB is fairly common in many countries, the findings hold importance for informing policy makers to implement intervention strategies on reducing children's access to SSB for promoting brain health.

Author Contributions: Conceptualization, Z.G. and Y.C. (Yajun Chen); Methodology, Z.G., S.H., Y.C. (Yican Chen), Y.Z., N.J. and S.Z.; Software, Z.G. and S.H.; Validation, Z.G., S.H. and Y.C. (Yajun Chen); Formal analysis, Z.G.; Investigation, Z.G., S.H., Y.C. (Yican Chen), Y.Z., N.J. and S.Z.; Resources, Z.G. and Y.C. (Yajun Chen); Data curation, Z.G.; Writing-original draft preparation, Z.G.; Writing-review and editing, Z.G., SH., Y.C. (Yican Chen), Y.Z., N.J., S.Z. and Y.C. (Yajun Chen); Visualization, Z.G. and S.H.; Supervision, Z.G. and Y.C. (Yajun Chen); Project administration, Z.G. and Y.C. (Yajun Chen); Funding acquisition, Y.C. (Yajun Chen). All authors have read and agreed to the published version of the manuscript.

Funding: This research was funded by the National Natural Science Foundation of China, grant number 81673193.

Institutional Review Board Statement: The study was conducted according to the guidelines of the Declaration of Helsinki, and approved by the Ethical Review Committee for Biomedical Research, Sun Yat-sen University (protocol code L2016-010).

Informed Consent Statement: Prior to data collection, all children and their parents/guardians gave their written informed consent.

Data Availability Statement: The data presented in this study are available on request from the corresponding author. The data are not publicly available since the participants of this study did not agree for their data to be shared publicly.

Acknowledgments: The authors acknowledge the support from all the team members and the participating students, teachers, parents, and local education and health staff.

Conflicts of Interest: The authors declare no conflict of interest.

\section{Appendix A}

Table A1. The distribution of scores of BRIEF among SSB consumption $(n=6387)$.

\begin{tabular}{llcc}
\hline \multirow{2}{*}{ BRIEF Scores } & \multicolumn{3}{c}{ SSB Consumption (Mean \pm Standard Deviation) } \\
\cline { 2 - 4 } & 0 Time/Week & 1 Time/Week & $\geq$ 2 Times/Week \\
\hline Inhibit & $49.44 \pm 9.55$ & $50.47 \pm 10.34$ & $51.20 \pm 10.59$ \\
Shift & $48.91 \pm 9.19$ & $50.15 \pm 10.04$ & $51.02 \pm 10.50$ \\
Emotional control & $49.38 \pm 9.40$ & $50.38 \pm 10.08$ & $51.18 \pm 10.72$ \\
Initiate & $48.89 \pm 9.39$ & $50.14 \pm 9.92$ & $51.38 \pm 10.39$ \\
Working memory & $49.27 \pm 9.62$ & $50.50 \pm 10.08$ & $51.52 \pm 10.17$ \\
Plan/organize & $48.84 \pm 9.47$ & $50.18 \pm 9.79$ & $51.70 \pm 10.31$ \\
Organization of materials & $49.04 \pm 9.75$ & $50.23 \pm 9.62$ & $51.63 \pm 10.33$ \\
Monitor & $49.23 \pm 9.79$ & $50.49 \pm 9.90$ & $51.60 \pm 10.07$ \\
BRI & $49.19 \pm 9.36$ & $50.41 \pm 10.20$ & $51.32 \pm 10.61$ \\
MI & $48.92 \pm 9.58$ & $50.30 \pm 9.83$ & $51.82 \pm 10.24$ \\
GEC & $48.94 \pm 9.51$ & $50.36 \pm 9.99$ & $51.79 \pm 10.35$ \\
\hline
\end{tabular}

Abbreviations: BRI, behavioral regulation index; BRIEF, Behavioral Rating Inventory of Executive Function; GEC: global executive composite; MI, metacognition; SSB, sugar-sweetened beverages. 
Table A2. Association between the total servings of SSB consumption a week and executive function $(n=6387)$.

\begin{tabular}{|c|c|c|c|}
\hline \multirow{2}{*}{ Executive Function } & \multicolumn{3}{|c|}{ Estimates (95\% Confidence Interval) } \\
\hline & Crude Model & Model $1^{a}$ & Model $2^{b}$ \\
\hline Inhibit & $0.31(0.13,0.50)^{c}$ & $0.30(0.12,0.49)^{\mathrm{C}}$ & $0.27(0.08,0.47)^{\mathrm{C}}$ \\
\hline Shift & $0.30(0.12,0.48)^{c}$ & $0.28(0.10,0.47)^{\mathrm{C}}$ & $0.22(0.03,0.41)^{c}$ \\
\hline Emotional control & $0.33(0.15,0.52)^{\mathrm{c}}$ & $0.36(0.17,0.55)^{\mathrm{c}}$ & $0.31(0.11,0.51)^{\mathrm{c}}$ \\
\hline Initiate & $0.39(0.21,0.57)^{\mathrm{c}}$ & $0.35(0.17,0.53)^{c}$ & $0.30(0.11,0.49)^{\mathrm{C}}$ \\
\hline Working memory & $0.35(0.17,0.53)^{c}$ & $0.36(0.18,0.54)^{\mathrm{c}}$ & $0.30(0.11,0.49)^{\mathrm{c}}$ \\
\hline Plan/organize & $0.41(0.23,0.59)^{\mathrm{c}}$ & $0.36(0.17,0.54)^{\mathrm{c}}$ & $0.29(0.11,0.48)^{\mathrm{C}}$ \\
\hline Organization of materials & $0.43(0.25,0.60)^{\mathrm{c}}$ & $0.40(0.22,0.58)^{\mathrm{c}}$ & $0.35(0.16,0.54)^{\mathrm{C}}$ \\
\hline Monitor & $0.32(0.15,0.50)^{\mathrm{C}}$ & $0.25(0.08,0.43)^{\mathrm{C}}$ & $0.21(0.03,0.40)^{\mathrm{C}}$ \\
\hline BRI & $0.36(0.18,0.55)^{c}$ & $0.36(0.18,0.55)^{\mathrm{c}}$ & $0.31(0.11,0.51)^{\mathrm{c}}$ \\
\hline MI & $0.43(0.25,0.61)^{\mathrm{c}}$ & $0.39(0.21,0.58)^{\mathrm{c}}$ & $0.34(0.14,0.53)^{\mathrm{C}}$ \\
\hline GEC & $0.44(0.25,0.62)^{c}$ & $0.41(0.22,0.59)^{\mathrm{c}}$ & $0.34(0.15,0.54)^{c}$ \\
\hline
\end{tabular}

Abbreviations: BRI, behavioral regulation index; GEC: global executive composite; MI, metacognition; SSB sugar-sweetened beverages. ${ }^{\text {a }}$ Adjusted for sex, age, siblings, monthly household income, parental education, parental smoking status, outdoor exercise and body mass index. ${ }^{\mathrm{b}}$ Additionally adjusted for fried food, fish or fish products, and milk, or dairy-products. ${ }^{c}$ Statistically significant association ( $p$ value $\left.<0.05\right)$.

Table A3. SSB and executive function stratified by sex, age, and weight $(n=6387)$.

\begin{tabular}{|c|c|c|c|}
\hline \multirow{2}{*}{ Group } & BRI & MI & GEC \\
\hline & Estimates $(95 \% \mathrm{CI})^{\mathrm{a}}$ & Estimates $(95 \% \mathrm{CI})^{\mathrm{a}}$ & Estimates $(95 \% \mathrm{CI})^{a}$ \\
\hline \multicolumn{4}{|l|}{ By Sex } \\
\hline \multicolumn{4}{|l|}{ Boys } \\
\hline 0 time/week & 0 (Reference) & 0 (Reference) & 0 (Reference) \\
\hline 1 time/week & $1.24(0.31,2.18)$ & $1.20(0.31,2.09)$ & $1.28(0.36,2.20)$ \\
\hline$\geq 2$ times/week & $2.30(1.35,3.24)$ & $2.88(1.99,3.78)$ & $2.89(1.97,3.81)$ \\
\hline \multicolumn{4}{|l|}{ Girls } \\
\hline 0 time/week & 0 (Reference) & 0 (Reference) & 0 (Reference) \\
\hline 1 time/week & $0.82(-0.02,1.67)$ & $1.16(0.28,2.04)$ & $1.18(0.30,2.06)$ \\
\hline$\geq 2$ times/week & $1.47(0.59,2.35)$ & $2.06(1.14,2.98)$ & $1.95(1.03,2.87)$ \\
\hline \multicolumn{4}{|l|}{ By Age } \\
\hline \multicolumn{4}{|l|}{$6-9$ years } \\
\hline 0 time/week & 0 (Reference) & 0 (Reference) & 0 (Reference) \\
\hline 1 time/week & $0.99(0.23,1.76)$ & $1.22(0.47,1.97)$ & $1.22(0.46,1.99)$ \\
\hline$\geq 2$ times/week & $1.36(0.55,2.17)$ & $2.03(1.24,2.82)$ & $1.91(1.10,2.73)$ \\
\hline \multicolumn{4}{|l|}{$10-12$ years } \\
\hline 0 time/week & 0 (Reference) & 0 (Reference) & 0 (Reference) \\
\hline 1 time/week & $1.08(-0.07,2.22)$ & $1.03(-0.12,2.18)$ & $1.18(0.02,2.34)$ \\
\hline$\geq 2$ times/week & $2.74(1.64,3.83)$ & $3.22(2.13,4.31)$ & $3.27(2.17,4.37)$ \\
\hline \multicolumn{4}{|l|}{ By $\bar{B} M I$} \\
\hline \multicolumn{4}{|l|}{ Normal weight } \\
\hline 0 time/week & 0 (Reference) & 0 (Reference) & 0 (Reference) \\
\hline 1 time/week & $0.76(0.03,1.48)$ & $0.83(0.12,1.54)$ & $0.91(0.19,1.64)$ \\
\hline$\geq 2$ times/week & $1.93(1.19,2.67)$ & $2.40(1.67,3.13)$ & $2.43(1.68,3.17)$ \\
\hline \multicolumn{4}{|l|}{ Overweight/obesity } \\
\hline 0 time/week & 0 (Reference) & 0 (Reference) & 0 (Reference) \\
\hline 1 time/week & $2.02(0.67,3.38)$ & $2.47(1.14,3.81)$ & $2.39(1.02,3.75)$ \\
\hline$\geq 2$ times/week & $1.67(0.32,3.03)$ & $2.86(1.53,4.19)$ & $2.57(1.21,3.92)$ \\
\hline
\end{tabular}

Abbreviations: BMI, body mass index; BRI, behavioral regulation index; CI, confidence interval; GEC: global executive composite; MI, metacognition; SSB, sugar-sweetened beverages. ${ }^{a}$ Adjusted for sex, age, siblings, monthly household income, parental education, parental smoking status, outdoor exercise, body mass index, fried food, fish or fish products, and milk, or dairy-products. ${ }^{b} p$ value for interaction (sex $\times$ SSB or age $\times$ SSB or $\mathrm{BMI} \times \mathrm{SSB})$ was statistically significant $(<0.05)$. 


\section{References}

1. Brand-Miller, J.C.; Barclay, A.W. Declining consumption of added sugars and sugar-sweetened beverages in Australia: A challenge for obesity prevention. Am. J. Clin. Nutr. 2017, 105, 854-863. [CrossRef] [PubMed]

2. Welsh, J.A.; Sharma, A.J.; Grellinger, L.; Vos, M.B. Consumption of added sugars is decreasing in the United States. Am. J. Clin. Nutr. 2011, 94, 726-734. [CrossRef]

3. Wang, L.; Martinez Steele, E.; Du, M.; Pomeranz, J.L.; O'Connor, L.E.; Herrick, K.A.; Luo, H.; Zhang, X.; Mozaffarian, D.; Zhang, F.F. Trends in consumption of ultraprocessed foods among US youths aged 2-19 years, 1999-2018. JAMA 2021, 326, 519-530 [CrossRef] [PubMed]

4. Popkin, B.M. Global nutrition dynamics: The world is shifting rapidly toward a diet linked with noncommunicable diseases. Am. J. Clin. Nutr. 2006, 84, 289-298. [CrossRef] [PubMed]

5. Popkin, B.M.; Hawkes, C. The sweetening of the global diet, particularly beverages: Patterns, trends and policy responses for diabetes prevention. Lancet Diabetes Endocrinol. 2016, 4, 174-186. [CrossRef]

6. Basu, S.; McKee, M.; Galea, G.; Stuckler, D. Relationship of soft drink consumption to global overweight, obesity, and diabetes: A cross-national analysis of 75 countries. Am. J. Public Health 2013, 103, 2071-2077. [CrossRef]

7. Malik, V.S.; Pan, A.; Willett, W.C.; Hu, F.B. Sugar-sweetened beverages and weight gain in children and adults: A systematic review and meta-analysis. Am. J. Clin. Nutr. 2013, 98, 1084-1102. [CrossRef] [PubMed]

8. Schwingshackl, L.; Schwedhelm, C.; Hoffmann, G.; Knuppel, S.; Iqbal, K.; Andriolo, V.; Bechthold, A.; Schlesinger, S.; Boeing, H. Food groups and risk of hypertension: A systematic review and dose-response meta-analysis of prospective studies. Adv. Nutr. 2017, 8, 793-803. [CrossRef]

9. $\mathrm{Hu}, \mathrm{F} . \mathrm{B}$. Resolved: There is sufficient scientific evidence that decreasing sugar-sweetened beverage consumption will reduce the prevalence of obesity and obesity-related diseases. Obes. Rev. 2013, 14, 606-619. [CrossRef]

10. Micha, R.; Penalvo, J.L.; Cudhea, F.; Imamura, F.; Rehm, C.D.; Mozaffarian, D. Association between dietary factors and mortality from heart disease, stroke, and type 2 diabetes in the United States. JAMA 2017, 317, 912-924. [CrossRef]

11. Singh, G.M.; Micha, R.; Khatibzadeh, S.; Lim, S.; Ezzati, M.; Mozaffarian, D. Estimated global, regional, and national disease burdens related to sugar-sweetened beverage consumption in 2010. Circulation 2015, 132, 639-666. [CrossRef]

12. Pan, A.; Hu, F.B. Effects of carbohydrates on satiety: Differences between liquid and solid food. Curr. Opin. Clin. Nutr. Metab. Care 2011, 14, 385-390. [CrossRef]

13. Bailey, R.L.; Fulgoni, V.L.; Cowan, A.E.; Gaine, P.C. Sources of added sugars in young children, adolescents, and adults with low and high intakes of added sugars. Nutrients 2018, 10, 102. [CrossRef]

14. Bray, G.A.; Nielsen, S.J.; Popkin, B.M. Consumption of high-fructose corn syrup in beverages may play a role in the epidemic of obesity. Am. J. Clin. Nutr. 2004, 79, 537-543. [CrossRef]

15. Ventura, E.E.; Davis, J.N.; Goran, M.I. Sugar content of popular sweetened beverages based on objective laboratory analysis: Focus on fructose content. Obesity 2011, 19, 868-874. [CrossRef] [PubMed]

16. Rodrigues, D.F.; do Carmo Henriques, M.C.; Oliveira, M.C.; Menezes-Garcia, Z.; Marques, P.E.; da Glória Souza, D.; Menezes, G.B.; Teixeira, M.M.; Ferreira, A.V.M. Acute intake of a high-fructose diet alters the balance of adipokine concentrations and induces neutrophil influx in the liver. J. Nutr. Biochem. 2014, 25, 388-394. [CrossRef]

17. Anderson, P. Assessment and development of executive function (EF) during childhood. Child Neuropsychol. 2002, 8, 71-82. [CrossRef] [PubMed]

18. Lezak, M.D.; Howieson, D.B.; Bigler, E.D.; Tranel, D. Neuropsychological Assessment, 5th ed.; Oxford University Press: New York, NY, USA, 2012.

19. Grandjean, P.; Landrigan, P.J. Neurobehavioural effects of developmental toxicity. Lancet Neurol. 2014, 13, 330-338. [CrossRef]

20. Romine, C.B.; Reynolds, C.R. A model of the development of frontal lobe functioning: Findings from a meta-analysis. Appl. Neuropsychol. 2005, 12, 190-201. [CrossRef]

21. Hsu, T.M.; Konanur, V.R.; Taing, L.; Usui, R.; Kayser, B.D.; Goran, M.I.; Kanoski, S.E. Effects of sucrose and high fructose corn syrup consumption on spatial memory function and hippocampal neuroinflammation in adolescent rats. Hippocampus 2015, 25, 227-239. [CrossRef]

22. Sanguesa, G.; Cascales, M.; Grinan, C.; Sanchez, R.M.; Roglans, N.; Pallas, M.; Laguna, J.C.; Alegret, M. Impairment of novel object recognition memory and brain insulin signaling in fructose- but not glucose-drinking female rats. Mol. Neurobiol. 2018, 55, 6984-6999. [CrossRef] [PubMed]

23. Agrawal, R.; Noble, E.; Vergnes, L.; Ying, Z.; Reue, K.; Gomez-Pinilla, F. Dietary fructose aggravates the pathobiology of traumatic brain injury by influencing energy homeostasis and plasticity. J. Cereb. Blood Flow Metab. 2016, 36, 941-953. [CrossRef]

24. Al-Sabah, R.; Al-Taiar, A.; Rahman, A.; Shaban, L.; Al-Harbi, A.; Mojiminiyi, O. Season of birth and sugary beverages are predictors of Raven's Standard Progressive Matrices Scores in adolescents. Sci. Rep. 2020, 10, 6145. [CrossRef]

25. Cohen, J.; Rifas-Shiman, S.L.; Young, J.; Oken, E. Associations of Prenatal and Child Sugar Intake With Child Cognition. Am. J. Prev. Med. 2018, 54, 727-735. [CrossRef]

26. Bleiweiss-Sande, R.; Chui, K.; Wright, C.; Amin, S.; Anzman-Frasca, S.; Sacheck, J.M. Associations between food group intake, cognition, and academic achievement in elementary schoolchildren. Nutrients 2019, 11, 2722. [CrossRef] [PubMed]

27. Wolraich, M.L.; Wilson, D.B.; White, J.W. The effect of sugar on behavior or cognition in children: A meta-analysis. JAMA 1995, 274, 1517-1521. [CrossRef] 
28. Gioia, G.A.; Isquith, P.K.; Retzlaff, P.D.; Espy, K.A. Confirmatory factor analysis of the behavior rating inventory of executive function (BRIEF) in a clinical sample. Child Neuropsychol. 2002, 8, 249-257. [CrossRef]

29. Roth, R.M.; Erdodi, L.A.; Culloch, L.J.; Isquith, P.K. Much ado about norming: The Behavior Rating Inventory of Executive Function. Child Neuropsychol. 2015, 21, 225-233. [CrossRef] [PubMed]

30. Qian, Y.; Wang, Y.F. Reliability and validity of behavior rating scale of executive function parent form for school age children in China. Beijing Da Xue Xue Bao Yi Xue Ban 2007, 39, 277-283.

31. Rosinger, A.; Herrick, K.; Gahche, J.; Park, S. Sugar-sweetened beverage consumption among U.S. youth, 2011-2014. NCHS Data Brief 2017, 271, 1-8.

32. Spagnuolo, M.S.; Iossa, S.; Cigliano, L. Sweet but bitter: Focus on fructose impact on brain function in rodent models. Nutrients 2020, 13, 1. [CrossRef] [PubMed] 